\title{
Mortality of a cohort in a polyamide-polyester factory in Lyon: a further follow up
}

\author{
MARTINE HOURS, ' ELISABETH CARDIS, ${ }^{2}$ ANNE MARCINIAK, 'P QUELIN, ${ }^{3}$ \\ J FABRY ${ }^{1}$
}

\begin{abstract}
From the Institut d'Epidemiologie,' Universite Claude Bernard, F-69008 Lyon, International Agency for Research on Cancer, ${ }^{2}$ F-69372 Lyon Cedex 08, and Service Médical Rhône-Poulenc, Usine Belle Etoile, Feyzin France
\end{abstract}

\begin{abstract}
In 1981-2 a retrospective study was undertaken in a polyamide-polyester factory in Lyon, France, to evaluate the effect of exposure to phthalates, nickel catalysers, and other chemicals in the work environment. The present paper reports the results of the follow up of this cohort up to July 1986. A slightly increased risk of cancers, in particular of the lung ( 44 cases), marginally related to exposure category but not significantly related to duration of exposure was found. The excess of skin cancers noted previously has disappeared, whereas an excess of cases of bladder cancer (based on seven cases) may be noted, mainly among nylon workers. The cohort is still young, however, and a continued follow up is likely to yield important information about the potential hazards associated with the nylon and tergal polymer industry.
\end{abstract}

Chemical workers have become increasingly concerned about the presence of carcinogens in their occupational environment. Their concern motivated the start, in 1981-2, of a retrospective cohort study of mortality in the Belle Etoile chemical factory owned by Rhône-Poulenc, a leading French chemical company, near Lyon, France. The results of this study, based on a follow up covering the period from 1950 to September 1981, were published previously. ${ }^{1}$ They indicated a slight excess of lung, laryngeal, and skin cancers, marginally related to industrial process, yet not significantly related to duration of employment. The cohort, however, was quite young at the end of that study and it was decided to extend the follow up of this stable cohort to elucidate the statistical associations noted previously.

The present pages report the results of the follow up of this cohort to July 1986. Apart from examining the associations noted previously, it also examines the issues of smoking and alcohol consumption as potential modifiers of the risk due to occupational exposure.

\section{Materials and methods}

The plant was built in 1950 and became fully operational in 1962. Altogether 4014 workers have been employed, with an average of 1900 workers at

Accepted 26 September 1988 any one time. It should be noted, however, that the plant currently employs only 1100 workers because of economic restrictions. There is round the clock production with $50 \%$ of the personnel working the day shift.

The activities are divided into administration, production, maintenance, and analysis and control. The production is highly specialised: polyamide (nylon 6.6: 51000 t/year), polyester (tergal: $55000 \mathrm{t} /$ year) and polyamid resin (150 t/year; since 1982 only). It is suspected that numerous potentially hazardous substances including ammonia, adipic acid, hexamethylene diamine, titanium oxide, Raney nickel, manganese and cobalt salts, terephthalic acid and its salts (including dimethylterephthalate), paraxylene, ethylene glycol, and methylene dianiline have at one time been present in the occupational environment. These substances are of interest because of reported adverse effects, including sterility ${ }^{2}$ and carcinogenicity (hepatic tumours in monkeys, ${ }^{3}$ mice, and rats $^{45}$ ) for diethylhexylphthalate (classified as possibly carcinogenic to man by the IARC). ${ }^{6 a}$ Phthalates, moreover, are the most used plastifiers and have the property of migrating into the liquids with which they are in contact. ${ }^{78}$ Ethylene glycol and its derivatives are being investigated because of reported haemolytic actions ${ }^{9}$ and bone marrow abnormalities observed in workers ${ }^{10}$ exposed to them.

Environmental protection measures have recently been carried out. They include considerable automa- 


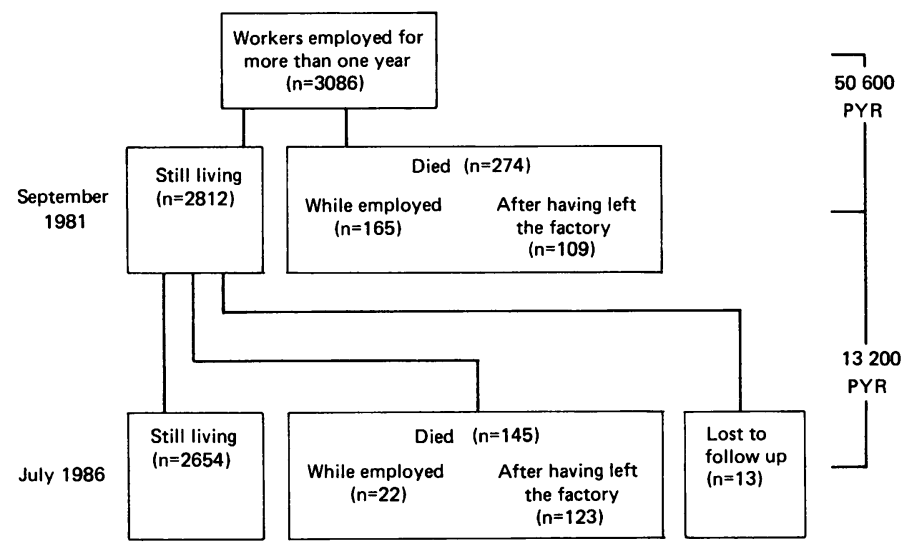

Summary of the follow ups. $P Y R=$ Person-years at risk. tion of the manufacturing processes since 1965 and the setting up of control rooms outside the production areas.

The physician in charge of the medical service directly supervises the collection of job information from factory records and the ascertainment of vital status. In France researchers are not allowed access to death certificates. The information on vital status was therefore obtained from records of the employee pension fund and from municipal records at the birthplace. Cause of death information was obtained from the personnel files of the medical service in the factory or from hospital records $(87.8 \%)$, from the treating physicians $(6.9 \%)$, or next of kin $(5 \cdot 3 \%)$. The causes thus identified were coded following the rules and nosology of the 9th International Classification of Diseases (ICD9). ${ }^{11}$ In addition, since 1978, the physician has been inquiring annually about the tobacco and alcohol consumption habits of the subjects still employed.

The cohort includes 3086 men, identified in 1981-2 and employed for more than one year in at least one area of the plant. The figure is a summary of the two follow ups. Women were excluded from the cohort because of their small number $(n=158)$.

The statistical analyses entailed comparing the mortality observed in the cohort with that expected in the French male population standardised for age and calendar year. Death rates for French men were obtained up to 1985 from the data banks of the World Health Organisation and the French National Institute of Health and Medical Research (INSERM). Computations of person-years of follow up and expected number of deaths were carried out using the classic modified life table analysis approach. ${ }^{12}$

The standardised mortality ratio (SMR) was used as a measure of deviation between the observed and expected number of deaths. The significance, and a
$95 \%$ confidence interval $(95 \% \mathrm{CI})$ for that estima; were derived based on the assumption of a Poiss distribution of the number of deaths.

Further analyses of mortality in relation to exposufe were performed. Because of the complexity exposure information for the substances of interes. the subjects were classified into four categories bas on their nylon/tergal employment history:

Nylon workers (25 635 person-years)-Subjects employed either in the production of nylon salt, whiकh $\infty$ began in 1952, or in that of the polymer nylon 6 ,, 0 which began in 1958. They were also exposed to Raneyo nickel, used as a catalyser. ${ }^{6 a}$

Tergal workers (15 142 person-years)-Subjeess employed in the production or in the polymerisationg of dimethylterephthalate, which began in 1956.

Maintenance workers (7386 person-years) $\stackrel{0}{\circ}$ Subjects exposed to the same substances as the응 workers in nylon and in tergal.

“Unexposed" workers (7535 person-years)-Main subjects employed in administration and in variods other positions, thought not to be exposed to either: nylon or tergal processes. It should be noted that 3 workers employed since 1982 in polyamide resin production are included in this category as they are not exposed in either nylon or tergal production. Theo possibility that they are exposed to other hazardous substances cannot be excluded but their number is윽 small (about 15 workers) and the start of the exposure is recent.

A fifth category, that of "mobile workers" (14 109 person-years), was also created and defined as" employees who worked in more than one of the initialo four categories. For analytical purposes, workers $N$ entered this category only when they started their: second job. In this process first jobs with less than oneI year's duration were ignored. Note that most of the? mobile workers were employees promoted from 
production to maintenance or to the central laboratory. Those employees holding only two jobs, one of which is in the unexposed category, were not classified as mobile but as workers of the employment category in which exposure is thought to have occurred.

The SMR values for different causes of death were calculated for the five employment categories, by time since first exposure, as a descriptive analysis of the differential risks between categories and their evolution over time. The few deaths observed for all sites of cancer except the lung did not warrant further analyses.

For sites where sufficient numbers of cases were found and where confounding by tobacco consumption was plausible, two additional sets of analyses were performed: one was aimed at testing for effects of smoking as a potential confounder using linear regression based on Poisson distribution of number of cases. ${ }^{13}$ For the other, a case-control study within the cohort was set up, with three controls per case, matched on age, and alive at the time of death of the case. Tests for association between risk of cancer and duration and time since first exposure were then performed using conditional logistic regression. ${ }^{14}$

\section{Results}

As reported previously, most of the employees in the cohort are French. They form a stable workforce with an average of 17.8 years in the factory. Eighty three per cent were hired between 1950 and 1964 . Fewer than half were over 30 at the time of hiring: the median age of the subjects in the study is currently 54.8 years compared with 50.5 at the end of the previous follow up period.

At the end of the follow up period, $86.5 \%$ of the cohort was still alive. Of the remainder, $13.5 \%$ was dead and only $0.4 \%$ lost to follow up. The circumstances of death are known for all but $8.8 \%$.

The follow up of the cohort consists of 69819 person-years, 13219 of which were accumulated since the end of the previous study period, mostly, as expected, in the age groups 35-54 and 55-74. The distribution of person-years at risk by time since beginning of employment is as follows: $39 \%$ in the $0-9$, $38 \%$ in the $10-19$, and $23 \%$ in the 20 or more years group.

Table 1 gives the mortality by specific cause. Total mortality is significantly lower in the cohort than in the reference population $(S M R=86 \cdot 1)$. As in the previous follow up, this is due to a deficit of deaths from non-malignant causes (SMRs of 19 for infectious diseases, 31 for circulatory diseases, 75 for respiratory diseases, $\mathbf{7 4}$ for diseases of the digestive system, and 75 for accidents and suicides). This deficit, however, is less pronounced than in the first follow up: SMRs of 70 and 84, respectively, for the first and second follow ups. SMRs for accidents and suicides and for nonmalignant diseases of the respiratory system are greater than 100 in the $1981-6$ follow up. The SMR for all causes also changes with time since first employment: it increases from 73 for subjects who started work less than 10 years previously to 100 for those who were hired over 20 years ago.

The number of deaths from cancer (all sites) is still significantly higher than expected (SMRs of 120 and 115 respectively in the first and the whole follow up). Excesses are observed for the following sites: larynx, intestine, rectum, lung, skin, bladder, leukaemia, and other malignant neoplasms. The excess is statistically significant at the 0.05 level only for the lung. It is marginally significant for the bladder.

The different tendencies observed in the two periods are as follows (table 2):

lung cancer mortality continues to be raised

Table 1 Mortality by specific cause (ICD 9) for 1950-86

\begin{tabular}{|c|c|c|c|}
\hline Cause & Observed No & $S M R$ & $95 \%$ Confidence interval \\
\hline $\begin{array}{l}\text { All causes } \\
\text { Cancers }(140 \cdot 0-208 \cdot 9) \text { : } \\
\text { Oral cavity and pharynx }(140 \cdot 0-149 \cdot 9) \\
\text { Oesophagus }(150 \cdot 0-150 \cdot 9) \\
\text { Stomach }(151 \cdot 0-151 \cdot 9) \\
\text { Intestine }(152 \cdot 0-153 \cdot 9) \\
\text { Rectum }(154 \cdot 0-154 \cdot 9) \\
\text { Larynx }(161 \cdot 0-161 \cdot 9) \\
\text { Lung }(162 \cdot 0-162 \cdot 9) \\
\text { Skin }(172 \cdot 0-173 \cdot 9) \\
\text { Prostate }(185 \cdot 0) \\
\text { Bladder }(188 \cdot 0-188 \cdot 9) \\
\text { Lymphatic and haemotopoietic tissue }(200 \cdot 0-208 \cdot 9) \\
\text { Leukaemia }(204 \cdot 0-208 \cdot 9) \\
\text { Other malignant neoplasms }(155 \cdot 0-160 \cdot 9,163 \cdot 0-165 \cdot 9 \text {, } \\
170 \cdot 0-171 \cdot 9,175,186 \cdot 0-187 \cdot 9,189 \cdot 0,199 \cdot 9)\end{array}$ & $\begin{array}{r}419 \\
163 \\
13 \\
12 \\
6 \\
8 \\
6 \\
12 \\
44 \\
3 \\
2 \\
7 \\
7 \\
5\end{array}$ & $\begin{array}{c}86 \cdot 1^{*} \\
115 \cdot 1^{*} \\
85.0 \\
101.5 \\
74.8 \\
115 \cdot 1 \\
158.6 \\
111.5 \\
139.6^{*} \\
239.5 \\
49.6 \\
203.8 \\
81.2 \\
119.1\end{array}$ & $\begin{array}{r}78-95 \\
98-134 \\
45-145 \\
52-177 \\
27-163 \\
50-227 \\
58-345 \\
58-195 \\
102-198 \\
30-700 \\
6-179 \\
82-421 \\
33-167 \\
39-278\end{array}$ \\
\hline
\end{tabular}

*Significant at the 0.05 level (one sided). 
Table 2 Mortality for specific causes by follow up period

\begin{tabular}{lccccc}
\hline & $1950-81$ & & \multicolumn{2}{c}{$1981-6$} \\
\cline { 2 - 3 } \cline { 5 - 6 } & Observed & $S M R$ & & Observed & $S M R$ \\
\hline Lung & 26 & $145 \cdot 8^{*}$ & & 18 & $134 \cdot 4$ \\
Bladder & 2 & $104 \cdot 6$ & 5 & $328 \cdot 1$ \\
Skin & 3 & $369 \cdot 5^{*}$ & 0 & 0 \\
All tumours & 102 & $119 \cdot 6^{*}$ & 61 & $109 \cdot 1$ \\
All causes & 274 & $82 \cdot 9^{*}$ & & 145 & $89 \cdot 6$ \\
\hline
\end{tabular}

*Significant at the 0.05 level.

(SMRs of 146 and 134 respectively in the first and second part of the follow up) although not significantly so in the period 1981-6;

the raised SMR for oesophagus noted previously has now disappeared;

the SMR for upper respiratory tract cancers in $1981-6$ is now less than 100 ;

no new skin cancer has appeared;

the risks of bladder cancer and of leukaemia have both risen (respectively from 105 to 204 and 68 to 120).

The distribution of observed and expected number of deaths from various causes is presented in tables 3 and 4 respectively by time since first exposure and by exposure category. The SMRs for all cancers and for lung and bladder cancers are significantly raised only in the group that started employment more than 20 years previously. Among the 18 new cases of lung cancer, 17 occurred in that group and only one in the group started employment 10 to 19 years previously.

Cancer mortality is higher than expected for nylon, tergal, and unexposed (administrative) workers. It is significantly so for unexposed workers in the period 1981-6 (SMR of 225 based on 15 cases) but is no longer significant among nylon and tergal workers. Significant increases are observed at individual sites only for lung and bladder cancers. For bladder cancer, the excess is mostly apparent among the nylon workers (five of the seven cases of bladder cancer: the case classified as mobile worked in nylon for 10 years before switching to maintenance) and among those who started work 20 or more years previously (five of the seven cases) (table 3 ). For lung cancer, the excess is statistically significant only among maintenance

Table 3 Distribution of SMR (observed) by time since first exposure

\begin{tabular}{lllllll}
\hline $\begin{array}{l}\text { Years since } \\
\text { first exposed }\end{array}$ & $\begin{array}{l}\text { All } \\
\text { malignancies }\end{array}$ & Lung & & Bladder \\
\hline $0-9$ & 120 & $(25)$ & 156 & $(6)$ & 264 & $(1)$ \\
$10-19$ & 104 & $(54)$ & 125 & $(14)$ & 85 & $(1)$ \\
$20-29$ & $122^{*}$ & $(84)$ & $146^{*}$ & $(24)$ & $265^{*}$ & $(5)$ \\
\hline
\end{tabular}

*Significant at the 0.05 level. workers but an excess is also present among tergal, $\overline{\bar{\alpha}}$ mobile, and unexposed workers.

For all causes of death, the SMRs are lower than 100 in all exposure categories except unexposed. The SMR is 75 and statistically different from 100 for $\overrightarrow{\vec{F}}$ mobile workers.

Further studies were carried out for lung cancer to응 test whether the difference in SMR between the nylon $\frac{\bar{c}}{\omega}$ workers and the others was due to a difference in $\vec{\nabla}$ smoking habits. In a stratified analysis using Poisson $\propto$ regression and adjusting for age and calendar period $\%$ the effect of number of cigarettes smoked (coded as: $0, \overrightarrow{0}$ $1-9,10-19, \geqslant 20$ cigarettes/day) was statistically significant but no effect of quitting and no interaction $\vec{\omega}$ with study group was significant. Table 5 presents the $\frac{\text { S }}{8}$ distribution of number of cigarettes smoked a day by $\mathbb{D}$ study group; there is no difference in mean lifetime? cigarette consumption between the employment categories. There is, however, a higher proportion $8 \mathrm{f}$ current smokers among non-exposed workers. The information on smoking was restricted to the $12 \overline{\mathrm{T}}$ subjects for whom it was collected; it is apparent! however, that those workers for whom the informo $\vec{s}$ tion is available tend to smoke more than the maxe $\mathbb{8}$ French population. ${ }^{15}$

Finally, in an effort to strengthen the association $\stackrel{\oplus}{\mathcal{P}} 3$ risk of lung cancer with exposure category a casocontrol study was performed within the cohort to test $\vec{c}$ the effects of total duration of employment in the $\infty$ factory and of duration of employment in tergal, $\overrightarrow{\mathrm{m}}$

Table 4 Standardised mortality ratio (observed) for selected causes of death according to employment category.

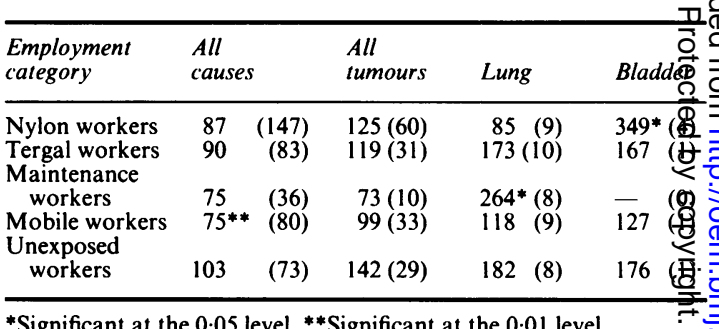

Table 5 Distribution of smoking by employment category (\%)

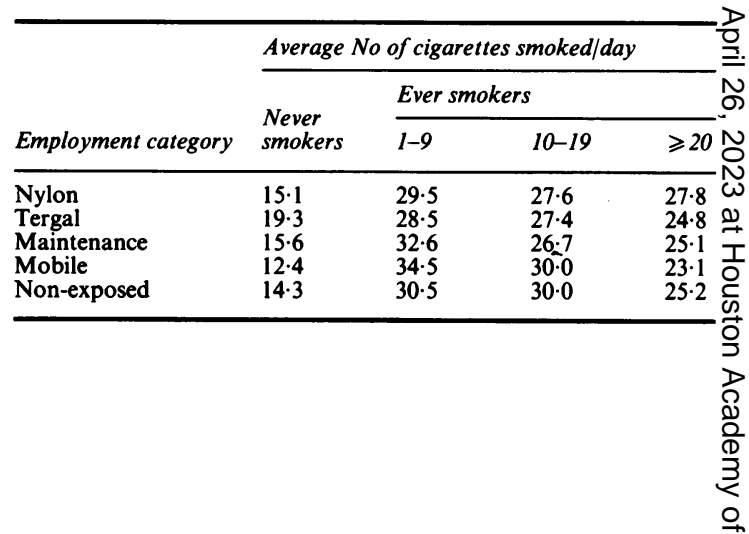


Table 6 Number of subjects and relative risks of lung cancer associated with duration of employment by employment category (case control within cohort study-univariate analyses)

\begin{tabular}{|c|c|c|c|c|}
\hline & 0 & $\begin{array}{l}1-9 \\
\text { years }\end{array}$ & $\begin{array}{l}10-19 \\
\text { years }\end{array}$ & $\begin{array}{l}>20 \\
\text { years }\end{array}$ \\
\hline $\begin{array}{l}\text { Administration: } \\
\text { No of cases } \\
\text { No of controls } \\
\text { RR } \\
95 \% \text { CI }\end{array}$ & $\begin{array}{c}33 \\
107 \\
-\quad 1.0 \\
-\end{array}$ & $\begin{array}{l}9 \\
7 \\
4 \cdot 2 \\
(1 \cdot 6-11 \cdot 1)\end{array}$ & $\begin{array}{l}1 \\
10 \\
0 \cdot 3 \\
(0 \cdot 2-2 \cdot 3)\end{array}$ & $\begin{array}{l}1 \\
8 \\
0 \cdot 4 \\
(0 \cdot 1-3 \cdot 2)\end{array}$ \\
\hline $\begin{array}{l}\text { Nylon: } \\
\text { No of cases } \\
\text { No of controls } \\
\text { RR } \\
95 \% \text { CI }\end{array}$ & $\begin{array}{c}30 \\
74 \\
-1.0 \\
-\end{array}$ & $\begin{array}{l}7 \\
26 \\
0 \cdot 7 \\
(0 \cdot 3-1 \cdot 7)\end{array}$ & $\begin{array}{l}6 \\
19 \\
0 \cdot 8 \\
(0 \cdot 3-2 \cdot 1)\end{array}$ & $\begin{array}{l}1 \\
13 \\
0 \cdot 2 \\
(0 \cdot 02-1 \cdot 4)\end{array}$ \\
\hline $\begin{array}{l}\text { Tergal: } \\
\text { No of cases } \\
\text { No of controls } \\
\text { RR } \\
95 \% \text { CI }\end{array}$ & $\begin{array}{c}34 \\
102 \\
1 \cdot 0 \\
-\quad\end{array}$ & $\begin{array}{l}1 \\
16 \\
0 \cdot 2 \\
(0 \cdot 0-1 \cdot 2)\end{array}$ & $\begin{array}{l}7 \\
10 \\
2 \cdot 1 \\
(0 \cdot 8-5 \cdot 7)\end{array}$ & $\begin{array}{l}2 \\
4 \\
1 \cdot 5 \\
(0 \cdot 3-8 \cdot 2)\end{array}$ \\
\hline $\begin{array}{l}\text { Maintenance: } \\
\text { No of cases } \\
\text { No of controls } \\
\text { RR } \\
95 \% \text { CI }\end{array}$ & $\begin{array}{r}34 \\
107 \\
-\quad 1.0 \\
-\end{array}$ & $\begin{array}{l}6 \\
17 \\
1 \cdot 1 \\
(0 \cdot 4-3 \cdot 0)\end{array}$ & $\begin{array}{l}1 \\
6 \\
0 \cdot 5 \\
(0 \cdot 1-4 \cdot 2)\end{array}$ & $\begin{array}{l}3 \\
2 \\
4 \cdot 7 \\
(0 \cdot 8-28 \cdot 3)\end{array}$ \\
\hline $\begin{array}{l}\text { Tergal environment: } \\
\text { No of cases } \\
\text { No of controls } \\
\text { RR } \\
95 \% \text { CI }\end{array}$ & $\begin{array}{l}18 \\
60 \\
-1 \cdot 0 \\
-\end{array}$ & $\begin{array}{l}9 \\
29 \\
1.0 \\
(0 \cdot 4-2 \cdot 5)\end{array}$ & $\begin{array}{l}11 \\
23 \\
1 \cdot 6 \\
(0 \cdot 7-3 \cdot 8)\end{array}$ & $\begin{array}{l}6 \\
20 \\
1 \cdot 0 \\
(0 \cdot 4-2 \cdot 7)\end{array}$ \\
\hline $\begin{array}{l}\text { Overall: } \\
\text { No of cases } \\
\text { No of controls } \\
\text { RR } \\
95 \% \text { CI }\end{array}$ & $\begin{array}{l}- \\
- \\
-\end{array}$ & $\begin{array}{l}15 \\
36 \\
1 \cdot 0 \\
-\end{array}$ & $\begin{array}{l}19 \\
50 \\
0 \cdot 9 \\
(0 \cdot 4-2 \cdot 0)\end{array}$ & $\begin{array}{l}10 \\
46 \\
0 \cdot 5 \\
(0 \cdot 2-1 \cdot 2)\end{array}$ \\
\hline
\end{tabular}

nylon, and in the "tergal environment" (defined as employment in one of tergal, mobile, or maintenance $^{1}$ ). Table 6 gives the relative risks by duration of employment. None of them was significant.

\section{Discussion}

The purpose of this follow up was to confirm or contradict the tentative results of a previous study carried out in 1981. In the present study the workforce is still young and $87 \%$ of the subjects are still alive. The follow up of this cohort is still good: only 13 workers could not be traced. Unknown causes account for $8 \%$ of the deaths. The data source has always been the medical records; there is therefore the possibility of discrepancies between the causes noted on the death certificate (unavailable to us but used in the compilation of national mortality statistics) and those noted by us and thus of a misclassification of cause of death. Such a misclassification bias, however, is probably negligible for the types of cancer of interest here.

A decrease in apparent healthy worker effect is observed in the second follow up for almost every nonmalignant cause of death; this is consistent with the aging of the population.
So far as cancers are concerned, the raised SMR (122) for oesophagus observed in the previous follow up has now disappeared $(S M R=101)$. The SMR for upper respiratory tract cancers has decreased from 110 to 96. No new case of skin cancer has appeared; the excess (based on three cases) noted previously is no longer significant.

The risk of bladder cancer has increased from 105 to 204. It is significantly overall in the period 1981-6 (SMR $=328$, based on five cases) and among workers who started employment over 20 years previously. With respect to employment category, the increase is significant among nylon workers only. The excess is based on few cases, however, and further investigation is needed to confirm it.

The risk of lung cancer continues to be significantly $(\mathrm{SMR}=140$ in this study compared with 146 in the previous follow up), though slightly less than observed previously. The excess is seen in all employment categories except nylon, which agrees with the observations in the previous study. The highest excess is observed among maintenance workers; these workers, as mentioned previously, are called on to repair and maintain equipment throughout the plant and are probably exposed to the widest range of potentially hazardous agents.

The hypothesis of a smoking explanation for lung cancer, inasmuch as it can be tested correctly with information available only for those still employed in 1978 , does not seem sufficient to explain all of the excess lung cancer in these exposure categories. The workers in this cohort tend to smoke more than the general population, yet the distribution of cases of lung cancer among employment categories does not reflect differences in smoking habits between these categories. The increase in bladder cancer, moreover, also a smoking associated site, is seen in nylon workers only, whereas that of lung cancer appears in all categories except nylon.

The hypothesis of an occupational exposure explanation of the increased risks was further tested with an analysis by duration of employment in each category. No effect of duration of employment or of time since start of employment was found. The existence of an association between lung cancer and occupational exposure in this industry cannot yet be either proved or discarded. Such an association, moreover, has also been suggested by Riboli $e t$ al in a study of workers exposed to phthalic anhydride and derivatives. ${ }^{16}$

In conclusion, the present study confirms a slightly increased risk of cancer (mostly lung) in the nylon and tergal industry. We may discard the excess risk of skin cancers observed previously as being due to chance. No further association or lack of one can be put forward with any certainty. 


\section{References}

1 Hours $\mathrm{M}$, Bertholon J, Esteve $\mathrm{J}$, et al. Mortality experience in a polyamide-polyester factory. Scand $J$ Work Environ Health 1987;12:455-60.

2 Oishi S, Hiraga K. Effect of phthalic acid esters on gonadal function in male rats. Bull Environ Contam Toxicol 1979;21: 65-7.

3 Jacobson MS, Kevy SV, Grand RS. Effect of a plasticizer leached from polyvinylchloride on the subhuman primate: a consequence of chronic transfusion therapy. J Lab Clin Med 1977;89:1066-79.

4 Ward JM, Diwan BA, Ohshima M, Hu H, Schuller HM, Rice JM. Tumor-initiating and promoting activities of di(2-ethylhexyl)phthalate in vivo and in vitro. Environ Health Perspect 1986;65:279-91.

5 Kluwe WM. Carcinogenic potential of phthalic acid esters and related compounds: structure-activity relationships. Environ Health Perspect 1986;65;271-8.

6 International Agency for Research on Cancer. Monographs on the evaluation of the carcinogenic risk of chemicals to humans, Vol 29. Some industrial chemicals and dyestuffs. Lyon: IARC, 1982.

6a International Agency for Research on Cancer. Monographs on the evaluation of the carcinogenic risks to humans. Suppl 7. Overall evaluation of carcinogenicity: an updating of IARC monographs volumes 1-42. Lyon: IARC, 1987.

7 Lederer J. Problems raised by the possible contamination of food by phthalates. Arch Belg 1986;44:3-44.
Hours, Cardis, Marciniak, Quelin, Fabry

8 Griffiths WC, Camara P, Lerner KS. Bis-(2-ethylhexyl) phthalate, $\overline{\bar{O}}$ an ubiquitous environmental contaminant. Ann Clin Lab Sci 1985;15:140-51.

9 Katz GV, Krasavage WJ, Terhaar CJ. Comparative acute and subchronic toxicity of ethylene glycol monopropyl ether and ethylene glycol monopropyl ether acetate. Environ Health $\overrightarrow{\bar{F}}$ Perspect 1984;57:165-75.

10 Cullen MR, Rado T, Waldron JA, Sparer J, Welch LS. Bone marrow injury in lithographers exposed to glycol ethers and $\underline{\sigma}$ organic solvents used in multicolor offset and ultraviolet curing $\overline{\bar{\omega}}$ printing processes. Arch Environ Health 1983;38:347-54.

11 World Health Organisation. Manual of the international statistical classification of diseases, injuries and causes of death. 9th rev. Vol 1. Geneva: WHO, 1975.

12 Coleman M, Douglas A, Hermon C, Peto J. Cohort study analysis $\vec{O}$ with a Fortran computer program. Int J Epidemiol 1986;15:134-7.

13 Breslow NE, Day NE Statistical methods in cancer research. Vol II. Lyon: International Agency for Research on Cancer, 1987. (IARC sci publ No 82.)

14 Breslow NE, Day NE. Statistical methods in cancer research. Vol I. Lyon: International Agency for Research on Cancer 1989 (IARC sci publ No 32.)

15 Institut National de la Statistique et des Etudes Economiques. consommateurs de boissons alcooliques et de tabac - enquête झ̛̣̆ la santé et les soins médicaux 1980-1981. Paris: INSEE, 198 $\overrightarrow{\mathrm{P}}$

16 Riboli E, Bai E, Berrino F, Merisi A. Mortality from lung cancer inh an acetylene and phthalic anhydride plant. A case-refereht $\vec{c}$ study. Scand J Work Environ Health 1983;9:455-62.

\section{Destruction of manuscripts}

From 1 July 1985 articles submitted for publication will not be returned. Authors whose papers are rejected will be advised of the decision and the manuscripts will be kept under security for three months to deal with any inquiries and then destroyed. 